\title{
Efficacy of Hip Posterolateral Complex Strengthening on Patients with Chronic Low Back Pain
}

\author{
Bid Dibyendunarayan Dhrubaprasad*, Riya Rushabh Shah and Thangamani Ramalingam Alagappan \\ Sarvajanik College of Physiotherapy, India
}

Submission: September 09, 2018; Published: February 25, 2019

*Corresponding author: Bid Dibyendunarayan Dhrubaprasad, Sarvajanik College of Physiotherapy, Gujarat, India

\begin{abstract}
Background: Although the strengthening of hip posterolateral complex (HPC) strengthening is largely used in physiotherapy practice for treating patients with hip and knee injuries, there is still a lack of proof regarding patients with chronic low back pain (CLBP). The efficacy of the HPC strengthening as an additional intervention to conventional treatment in a well-designed trial with statistic power needs to be tested.

Methods: An experimental trial with a sample size of 50 CLBP subjects, divided into two groups, 25 in each group was used. Group Areceived HPC musculature strengthening along with Conventional Physiotherapy Program and Group-B received Conventional Physiotherapy Program only. All the participants underwent a pre-treatment assessment at the start ( 0 week) and post-treatment assessment at the end of 2 weeks and 4 weeks using the NPRS, ODI, and HPC muscle strength measurement.
\end{abstract}

Results: The present study showed that both the treatment group attained statistically meaningful improvement in Pain (NPRS), Disability (ODI), and Strength.

Conclusion: HPC musculature strengthening exercises can be used as an adjunct in reducing pain, minimizing disability and improving the strength of HPC muscles in subjects with CLBP.

Keywords: Chronic low back pain; Conventional back exercises; Hip posterolateral complex musculature strengthening exercises; Oswestry disability index; Hand-held dynamometer.

Abbrevations: RHES: Right Hip Extensor Strength; RHAS: Right Hip Abductor Strength, RHERS: Right Hip External Rotation Strength; HPC: hip posterolateral complex; LBP: Low back pain; GROC: Global rating of change scale; ODI: Oswestry Disability Index; HHD: hand-held dynamometer

\section{Introduction}

Low back pain (LBP) can be defined as "any form of pain, muscle tension, or stiffness localized between the costal margins and the inferior gluteal folds, with or without radiation into the lower limbs". [1] LBP is the most common musculoskeletal problem experienced by $70-85 \%$ of the general population at some point in time in their lives [2]. LBP creates a substantial personal, community and financial burden globally [3-5]. Low back pain is connected with the heavy manual jobs in which repeated forward bending and lifting activities are required [6]. Other factors associated with low back pain, include poor muscle endurance, altered muscle firing rates, muscular imbalance and inflexibility of lower extremities [7-9]. In physiotherapy practice, decreased endurance capacity of back extensor muscles has been linked with CLBP. $[10,11]$ A biomechanical approach that has been described is that a weakness of the hip abductors, extensors, and lateral rotators musculature (hip posterolateral complex-HPC) would lead to undue contralateral pelvic drop during weight-bearing activities such as walking, running, climbing up or downstairs, generating an overloading the lumbar area. Although the strengthening of the HPC is largely used in physiotherapy practice for treating patients with hip and knee injuries, there is still a lack of proof regarding patients with LBP. Therefore, the question remains to be tested i.e. the efficacy of the HPC strengthening as an additional intervention to conventional treatment in a welldesigned trial with adequate statistical power [12].

Due to the hip joint's proximity to the lumbar spine, clinical examination of a hip range of motion (ROM), strength and function are routinely performed when assessing LBP which have led to many studies examining these relationships to LBP. Due to the heterogeneous nature of LBP, various asymmetries of hip ROM and possible altered hip muscle recruitment could be associated with LBP. Muscles that act on the hip joint and link the hip to the pelvis and spine have been studied in association with LBP with varying results. Regardless of the actual clinical causes, all those who complain of LBP experience a decline in muscle strength, muscle endurance, and flexibility, and restriction of lumbar and lower extremity joint range of motion $[13,14]$. 
Most clinical practice guidelines prescribe exercise for the management of CLBP [15]. One of the major challenges for researchers in the field of LBP is to provide proof regarding the treatment, which provides the most benefit for subgroups of patients with low back pain [16]. Biomechanically, the hip extensors and abductors play a major role in all ambulatory activities, stabilizing the trunk and hip and helping to transfer force from the lower extremities to the pelvis $[17,18]$. The gluteus maximus plays a key role in stabilizing the pelvis during trunk rotation or when the centre of gravity is grossly shifted, while the hamstrings play a more significant role during activities such as running or jumping $[17,18]$. The gluteus Medius/minimums are the major stabilizers of the pelvis during single limb stance [19]. Activation of these hip abductors prevents the Trendelenburg sign whereby the pelvis contralateral to the weight-bearing extremity tilts downward during the stance phase of gait. The hip musculature thus plays a major role in transferring forces from the lower extremity up towards the spine during upright activities. Poor endurance and the delayed firing of the gluteus maximus and gluteus Medius muscles have earlier been noted in persons with CLBP [20-23]. So, this study was designed to determine the efficacy of HPC strengthening in addition to conventional therapy in comparison to conventional therapy alone on reducing pain, improving the strength of HPC musculature and reducing disability thus improving functionality in patients with CLBP.

\section{Materials and Methods}

A sample size of 46 patients which was calculated based on a pilot study conducted using 8 subjects, 4 in each group with effect size 0.35 , power 0.8 and level of significance $(\alpha) 0.05$, using G power 3.2.1.9 software. To take care of dropouts additional $10 \%$ subjects were added. Hence each group received 25 subjects with a total sample size of 50 .

\section{Inclusion criteria}

a) Both males and females of age group within 30-50 years

b) Numerical pain rating scores from 3 to 6

c) Consistent daily LBP for a minimum of 12 weeks

d) Location of pain is below the costal margin and above the gluteal folds with or without leg pain.

\section{Exclusion criteria}

a) Red Flag' symptoms including, a history of major trauma, persistent night pain, bladder or bowel dysfunction, and/or lower extremity neurological deficit;

b) Previous surgery to the lumbar spine, abdomen, pelvis, or hip;

c) Use of any radiological interventions or injections in the past 3 months;

d) Any contraindication for exercise therapy (e.g. uncontrolled hypertension, previous myocardial infarction, cardiovascular disease, peripheral vascular disease, respiratory disorders)

e) Patients unable to perform isometric contraction and hold it for 30 seconds while testing;

f) Any pain originated because of SI pathology;

g) Menstruation during testing days; and

h) Individuals incapable of understanding and answering the questionnaire.

Ethical approval from the Institutional ethics committee of the Sarvanana College of Physiotherapy, Surat, was obtained (Ref. No. SMT/SCOP/IEC/17-18/771 dated 27-3-2018).

\section{Procedure}

After a preliminary selection based on the inclusion and exclusion criteria, subjects were randomly allocated into two groups, Group A- received HPC musculature Strengthening along with Conventional Physiotherapy Program and Group-B received Conventional Physiotherapy Program, five days per week for four weeks (Appendix-1). A written informed consent was obtained from all the participants before a pre-treatment assessment. Prior to treatment baseline data were documented using the NPRS, ODI, and HPC muscle strength measurement. The HPC strength was measured using hand-held dynamometer (HHD), Pain intensity was measured using NPRS, disability was evaluated by Oswestry Disability Index (ODI) and at the end of the intervention, patient satisfaction rate was recorded by using Global rating of change scale (GROC). These data were then compared with the data collected after the intervention at the end of 2 nd week and 4 th week for both the groups to see its effect on the subjects.

Hip-strength values were obtained using an HHD (Saehan Corporation, Changwon, Korea) with an adapted-curved, foam transducer pad used for patient comfort. Hip muscles assessed included the hip extensors (Gluteus maximus), abductors (Gluteus Medius), and external rotators. Muscle testing was done by the "make test" method of muscle testing in which the patient applied a maximum muscle contraction to the physiotherapist's hand holding the dynamometer [24]. Majority of the patients were right leg dominant, hence the right hip muscles strength (RHES-Right hip extensor strength, RHAS-Right hip abductor strength and RHERS- Right hip external rotators strength) were tested for the ease of description of data. Though data was also taken for left hip as well, that is not described here to reduce the narrative.

After the clinician explained each test procedure, patients were allowed a practice trial for familiarization before each individual test. Patients were instructed to increase their force over a 5-second time interval. A standard cue of "ready, set, go" was used by the physiotherapist to start the testing process. Verbal encouragement via the physiotherapist saying the word push repeatedly in a loud voice was provided during the muscle contraction. Patients performed 2 maximal contractions for each 
tested motion $[25,26]$. The greatest value on the HHD of the 2 tests was recorded. Between tests, a period of 30 seconds for rest was allowed.

\section{Statistical Analyses}

Normality of data was checked using the Shapiro-Wilk Test. The data have been presented as a mean and standard deviation or median and IQR for all the outcome measures. As the outcome measures were measured at multiple time intervals: (0 week, post 2 weeks and post 4 weeks) for within and between group comparisons; Friedman ANOVA and Mann Whitney U test were used. Statistical significance was set at $\mathrm{P}<0.05$ for all statistical analyses. All data analyses were done using IBM SPSS statistical software version 20.0 .

\section{Results}

The study was conducted on 50 CLBP subjects, 25 in each group. The mean age and BMI of the subjects in the experimental group were $39.56 \pm 6.545$ years and $26.58 \pm 3.456 \mathrm{Kg} / \mathrm{m}^{2}$ respectively, while in the control group were $40.52 \pm 7.287$ years and $26.169 \pm 3.797 \mathrm{Kg} / \mathrm{m}^{2}$ respectively (Table 1 ). The gender distribution in the experimental group was 28\% males and $72 \%$ females; while in the control group was $24 \%$ males and $76 \%$ females. Also, the groups were similar at 0 week for all outcome measures with p-value $>0.05$ (Table 1 ). A within and between group comparisons of HPC strength (RHES, RHAS, and RHERS), Pain intensity (NPRS) and disability (ODI) were shown in (Table $2)$. And at the end of the intervention patient satisfaction rate (GROC) results were shown in (Table 3).

Table 1: Demographic Characteristics of CLPB patients.

\begin{tabular}{|c|c|c|c|}
\hline Demographic Variables & $\begin{array}{c}\text { HPC Musculature Strengthening } \\
\text { Exercise Group (N=25) Mean } \pm \text { SD }\end{array}$ & $\begin{array}{c}\text { Conventional Physiotherapy } \\
\text { Group (N=25) Mean } \pm \text { SD }\end{array}$ & P-values \\
\hline Age & $39.56 \pm 6.545$ & $40.52 \pm 7.287$ & 0.626 \\
\hline Gender (Male/Female) & $7 / 18$ & $6 / 19$ & -- \\
\hline Height & $159.660 \pm 6.774$ & $159.640 \pm 5.999$ & 0.991 \\
\hline Weight & $67.976 \pm 11.058$ & $66.760 \pm 10.944$ & 0.698 \\
\hline BMI & $26.58 \pm 3.456$ & $26.169 \pm 3.797$ & 0.726 \\
\hline
\end{tabular}

Table 2: Between and within group comparisons of outcome measures.

\begin{tabular}{|c|c|c|c|c|c|c|}
\hline \multirow{2}{*}{\multicolumn{2}{|c|}{ Measurement }} & \multicolumn{2}{|c|}{$\begin{array}{l}\text { HPC Musculature Strengthening } \\
\text { Exercise Group }\end{array}$} & \multicolumn{2}{|c|}{ Conventional Physiotherapy Group } & \multirow{3}{*}{$\begin{array}{c}\text { P Value } \\
0.287\end{array}$} \\
\hline & & Mean \pm SD & Median (IQR) & Mean \pm SD & Median (IQR) & \\
\hline \multirow{4}{*}{ RHES } & 0 week & $2.32 \pm 0.557$ & $2(2-3)$ & $2.16 \pm 0.374$ & $2(2-2)$ & \\
\hline & Post 2 weeks & $4.00 \pm 0.707$ & $4(4-4)$ & $3.24 \pm 0.723$ & $3(3-4)$ & 0.001 \\
\hline & Post 4 weeks & $5.76 \pm 0.926$ & $6(5-6)$ & $4.08 \pm 0.702$ & $4(4-4)$ & 0 \\
\hline & P-value & \multicolumn{2}{|c|}{0} & \multicolumn{3}{|c|}{0} \\
\hline \multirow{4}{*}{ RHAS } & 0week & $2.60 \pm 0.645$ & $3(2-3)$ & $2.56 \pm 0.507$ & $3(2-3)$ & 0.974 \\
\hline & Post 2 weeks & $4.16 \pm 0.688$ & $4(4-5)$ & $3.52 \pm 0.586$ & $4(3-4)$ & 0.002 \\
\hline & Post 4 weeks & $6.00 \pm 1.118$ & $6(5-7)$ & $4.32 \pm 0.627$ & $4(4-5)$ & 0 \\
\hline & P-value & \multicolumn{2}{|c|}{0} & \multicolumn{3}{|c|}{0} \\
\hline \multirow{4}{*}{ RHERS } & 0week & $1.64 \pm 0.757$ & $2(1-2)$ & $1.40 \pm 0.577$ & $1(1-2)$ & 0.241 \\
\hline & Post 2 weeks & $2.72 \pm 1.021$ & $2(2-3)$ & $2.00 \pm 0.913$ & $2(1-2.50)$ & 0.01 \\
\hline & Post 4 weeks & $3.28 \pm 1.208$ & $3(2.50-3.50)$ & $2.44 \pm 0.917$ & $2(2-3)$ & 0.003 \\
\hline & P-value & \multicolumn{2}{|c|}{0.001} & \multicolumn{3}{|c|}{0.001} \\
\hline \multirow{4}{*}{ NPRS } & 0week & $5.44 \pm 0.583$ & $5(5-6)$ & $5.60 \pm 0.500$ & $6(5-6)$ & 0.343 \\
\hline & Post 2 weeks & $3.36 \pm 0.700$ & $3(3-4)$ & $3.96 \pm 0.676$ & $4(3.50-4)$ & 0.007 \\
\hline & Post 4 weeks & $1.48 \pm 0.714$ & $2(1-2)$ & $2.36 \pm 0.757$ & $2(2-3)$ & 0 \\
\hline & P-value & \multicolumn{2}{|c|}{0} & \multicolumn{3}{|c|}{0} \\
\hline \multirow{4}{*}{ ODI } & 0week & $17.36 \pm 1.977$ & 18 (17-19) & $17.76 \pm 1.234$ & $18(16.50-19)$ & 0.6 \\
\hline & Post 2 weeks & $11.92 \pm 1.605$ & $12(11-13)$ & $13.44 \pm 2.022$ & $13(11.50-15)$ & 0.014 \\
\hline & Post 4 weeks & $8.00 \pm 1.658$ & $8(7-9)$ & $9.80 \pm 1.915$ & $10(8.50-11)$ & 0.002 \\
\hline & P-value & \multicolumn{2}{|c|}{0} & \multicolumn{3}{|c|}{0} \\
\hline
\end{tabular}


Table 3: Between group comparison for GROC.

\begin{tabular}{|c|c|c|c|c|c|}
\hline \multirow{2}{*}{ Measurements } & \multicolumn{2}{|c|}{ HPC Musculature Strengthening Exercise Group } & \multicolumn{2}{|c|}{ Conventional Physiotherapy Group } & \multirow{2}{*}{ P-Value } \\
\cline { 2 - 5 } & Mean \pm SD & Median (IQR) & Mean \pm SD & Median (IQR) & $6(5-7)$ \\
\hline Post 4 weeks & $6.40 \pm 0.707$ & $6(5-7)$ & $5.28 \pm 0.678$ & 0 \\
\hline
\end{tabular}

\section{Discussion}

The study was attempted to find out the efficacy of HPC Strengthening along with Conventional Physiotherapy Program and only Conventional Physiotherapy Program on patients with CLBP. The study results showed that both the treatment group attained statistically meaningful improvement in Pain (NPRS), Disability (ODI), and Strength (RHES, RHAS, \& RHERS) in both the groups. Both the treatment groups attained a significant improvement in HPC strength for right hip, but the clinically significant difference cannot be commented because of lack of normative data for lower limb muscle strength measurement via HHD in CLBP patients. Similar results were also found for the left hip musculature strength though the data and results are not discussed for the left hip musculature to reduce the narrative. The HPC musculature strengthening exercise group showed more improvement in HPC strength compared to the conventional physiotherapy group. But when considering pain reduction, the study results showed that both treatment groups attained a significant reduction in pain not only statistically but also with the clinically significant important difference of NPRS [27]. And the results for disability revealed that both treatment groups attained a significant reduction in disability, but the experimental group showed a statistically significant difference of ODI than the control group without the clinically significant difference [28] (Table 2). Overall significant improvement in the Global Rating of Change Scale at 4 th week indicated more satisfaction in HPC musculature strengthening exercise group (Table 3 ).

Similar studies showing the results, in line with the present study for pain, disability and HPC muscle strength and its relation to CLBP are described below:

\section{Is there any correlation between Hip musculature and Back Pain?}

Arab \& Nourbakhsh [29] showed that subjects of LBP with or without ITB tightness have significantly reduced the strength of hip abductor muscles. Embaby \& Abdallah [30] found that the clinical instructors with LBP are more likely to have a greater trunk and gluteus medius muscle fatigue than asymptomatic persons. Himmelreich et al. [31] suggested that low back pain conditions are connected with changes in the level and duration of gluteus maximus activity under different gait patterns. Reiman et al. [32] concluded that best current evidence supports the link between impairments at the hip and LBP. Research also suggested that decreased hip ROM, hip-extensor strength, and hip-adductor or flexor endurance might contribute to pain in the lumbar area. Because of this emerging relationship, they suggested that hipjoint ROM, muscle performance, anatomical alignment, and mobility should be considered during the examination of patients with LBP. Cooper et al. [33] concluded that the gluteus medius weakness and gluteal muscle tenderness are common indicators in people with CLBP. These above-mentioned studies indicate one thing in common that in the case of CLBP, there exists hip extensor and hip abductor muscles weakness. The same has been found true in our study as well.

\section{How does HPC musculature strengthening affect pain, disability, and HPC strength?}

Biomechanically, the hip extensors and abductors play a major role in all ambulatory activities, stabilizing the trunk and hip and helping to transfer force from the lower extremities to the pelvis $[17,18]$. The gluteus maximus plays a major role in stabilizing the pelvis during trunk rotation or when the center of gravity is grossly shifted, while the hamstrings play a more significant role during activities such as running or jumping $[17,18]$. The gluteus medius/minimus are the major stabilizers of the pelvis during single limb stance [19]. Activation of these hip abductors prevents the Trendelenburg sign whereby the pelvis contralateral to the weight-bearing extremity tilts downward during the stance phase of gait. The hip musculature thus plays a significant role in transferring forces from the lower extremity up towards the spine during upright activities. Poor endurance and delayed the firing of the hip extensor (gluteus maximus) and abductor (gluteus medius) muscles have previously been noted in individuals with CLBP [20-23].

Ui-Cheol Jeong et al. [34] showed that lumbar segmental stabilization exercise plus exercise to strengthen the muscles of the gluteus lead to in a greater reduction in LBP disability index and increase in lumbar muscle strength and increased balance ability. Also, Kendall et al. [35] showed that both lumbopelvic motor control group and combined lumbopelvic motor control and progressive hip strengthening exercise therapy program group show a reduction in pain and disability for individuals with CNSLBP. Sang Wk Lee \& Suhn Yeop Kim [13] also found that the performance of hip exercises by CLBP patients with lumbar instability is more effective at reducing low-back pain and level of disability. Kankaanpaa et al. [23] found that the gluteus maximus muscles are more fatigable in CLBP patients than in healthy control. Similarly, our study proves that by improving the HPC musculature strength in CLBP patients gives better clinical results in terms of pain and disability in CLBP patients.

The present study has few limitations. Such as non-blinded clinicians, lack of long-term outcomes data, relatively small sample size and data collection not by an independent observer. A power analysis was calculated based on a pilot data of eight participants. A large sample size with more diverse population would allow greater generalisation of results to clinical practice. 


\section{Conclusion}

HPC musculature strengthening in addition to conventional physiotherapy exercise achieved improvement in pain, disability, and strength of HPC muscles; and showed better satisfaction rate at the end of the intervention. Thus, HPC musculature strengthening exercise can be used as an additional exercise in reducing pain, minimizing disability and improving the strength of HPC Muscles in subjects with CLBP.

\section{Acknowledgement}

We acknowledge the support of all the physiotherapists of Lockhat and Moolla Sarvajanik Hospital, Surat; Ayurvedic Hospital, Surat; and Sahyog Physiotherapy \& Fitness Centre, Surat.

\section{References}

1. Bala K, Gakhar M, Jagga V (2012) Effect of endurance training of trunk extensor muscles on pain and endurance in patients with sub-acute nonspecific low backache. Journal of Exercise Science and Physiotherapy 8(2): 82-86.

2. Andersson GB (1999) Epidemiological features of chronic low-back pain. The lancet 354(9178): 581-5.

3. Dionne CE, Dunn KM, Croft PR (2006) Does back pain prevalence really decrease with increasing age? A systematic review. Age and ageing 35(3): 229-234.

4. Rapoport J, Jacobs P, Bell NR, Klarenbach S (2004) Refining the measurement of the economic burden of chronic diseases in Canada. Chronic diseases in Canada 25(1): 13-21.

5. Deyo RA, Cherkin D, Conrad D, Volinn E (1991) Cost, controversy, crisis: low back pain and the health of the public. Annual review of public health 12(1): 141-156.

6. Marras WS, Lavender SA, Leurgans SE, Rajulu SL, Allread WG et.al (1993) The role of dynamic three-dimensional trunk motion in occupationally-related low back disorders. The effects of workplace factors, trunk position, and trunk motion characteristics on risk of injury. Spine 18(5): 617-628.

7. Biering-sørensen F (1984) Physical measurements as risk indicators for low-back trouble over a one-year period. Spine 9(2): 106-119.

8. Giles LG, Taylor JR (1981) Low-back pain associated with leg length inequality. Spine 6(5): 510-521.

9. Nadler SF, Wu KD, Galski T, Feinberg JH (1998) Low back pain in college athletes. A prospective study correlating lower extremity overuse or acquired ligamentous laxity with low back pain. Spine 23(7): 828-833.

10. Nicolaisen T, Jorgensen K (1985) Trunk strength, back muscle endurance and low-back trouble. Scandinavian journal of rehabilitation medicine 17(3): 121-127.

11. Hultman G, Nordin M, Saraste H, Ohlsen H (1993) Body composition, endurance, strength, cross-sectional area, and density of MM erector spinae in men with and without low back pain. Journal of spinal disorders 6(2): 114-123.

12. Neto MG Hip posterolateral complex strengthening in patients with chronic nonspecific low back pain: a randomized clinical trial.

13. Lee $S$ (2015) Effects of hip exercises for chronic low-back pain patients with lumbar instability. J Phys Ther Sci 27(2): 345-348.

14. Stuart M McGill, Grenier S, Kavcic N, Cholewicki J (2003) Coordination of muscle activity to assure stability of the lumbar spine. Journal of electromyography and kinesiology: official journal of the International Society of Electrophysiological Kinesiology 13(4): 353-359.
15. Costa LO, Maher CG, Latimer J, Hodges PW, Herbert RD et_al. (2009) Motor control exercise for chronic low back pain: a randomized placebo-controlled trial. Physical therapy 89(12): 1275-1286.

16. Van Tulder M, Malmivaara A, Esmail R, Koes B (2000) Exercise therapy for low back pain: a systematic review within the framework of the cochrane collaboration back review group. Spine 25(21): 2784-2796.

17. Lyons K, Perry J, Gronley JK, Barnes L, Antonelli D (1983) Timing and relative intensity of hip extensor and abductor muscle action during level and stair ambulation. An EMG studies. Physical therapy 63(10): 1597-1605.

18. Joseph J, Nightingale A (1954) Electromyography of muscles of posture: thigh muscles in males. The Journal of Physiology 126(1): 81-85.

19. Inman VT (1947) Functional aspects of the abductor muscles of the hip. J Bone Joint Surg Am 29(3): 607-619.

20. Beckman SM, Buchanan TS (1995) Ankle inversion injury and hypermobility: effect on hip and ankle muscle electromyography onset latency. Archives of physical medicine and rehabilitation 76(12): 11381143.

21. Bullock-Saxton JE (1994) Local sensation changes and altered hip muscle function following severe ankle sprain. Physical therapy discussion 28-31, 74(1): 17-28.

22. Devita P, Hunter PB, Skelly WA (1992) Effects of a functional knee brace on the biomechanics of running. Medicine and science in sports and exercise 24(7): 797-806.

23. Kankaanpaa M, Taimela S, Laaksonen D, Hanninen O, Airaksinen 0 (1998) Back and hip extensor fatigability in chronic low back pain patients and controls. Arch Phys Med Rehabil 79(4): 412-417.

24. Reese NB (2005) Muscle and Sensory Testing. Philadelphia, PA: Elsevier Saunders, USA, pp. 253-301.

25. Cichanowski HR, Schmitt JS, Johnson RJ, Niemuth PE (2007) Hip strength in collegiate female athletes with patellofemoral pain. Medicine and science in sports and exercise 39(8): 1227-1232.

26. Krause DA, Schlagel SJ, Stember BM, Zoetewey JE, Hollman JH (2007) Influence of lever arm and stabilization on measures of hip abduction and adduction torque obtained by hand-held dynamometry. Arch Phys Med Rehabil 88(1): 37-42.

27. Childs JD, Piva SR, Fritz JM (2005) Responsiveness of the numeric pain rating scale in patients with low back pain. Spine. 30(11): 1331-1334.

28. Copay AG, Glassman SD, Subach BR, Berven S, Schuler TC, et_al. (2008) Minimum clinically important difference in lumbar spine surgery patients: a choice of methods using the Oswestry Disability Index, Medical Outcomes Study questionnaire Short Form 36, and Pain Scales. The Spine Journal 8(6): 968-974.

29. Arab AM, Nourbakhsh MR (2010) The relationship between hip abductor muscle strength and iliotibial band tightness in individuals with low back pain. Chiropractic \& osteopathy 18: 1.

30. Embaby EA, Abdallah AAA (2014) Trunk and Gluteus-Medius Muscles' Fatigability during Occupational Standing in Clinical Instructors with Low Back Pain. International Journal of Medical, Health, Biomedical, Bioengineering and Pharmaceutical Engineering 8(3): 171-176.

31. Himmelreich H, Vogtb L, Banzerb W (2008) Gluteal muscle recruitment during level, incline and stair ambulation in healthy subjects and chronic low back pain patients. Journal of Back and Musculoskeletal Rehabilitation 21: 193-199.

32. Reiman MP, Weisbach PC, Glynn PE (2009) The Hip's Influence on Low Back Pain: A Distal Link to a Proximal Problem. Journal of Sport Rehabilitation 18(1): 24-32.

33. Cooper NA, Scavo KM, Strickland KJ, Tipayamongkol N, Nicholson JD, et al. (2016) Prevalence of gluteus medius weakness in people with 
chronic low back pain compared to healthy controls. European spine journal 25(4): 1258-1265.

34. Jeong UC (2015) The effects of gluteus muscle strengthening exercise and lumbar stabilization 27(12): 3813-3816.
35. Kendall KD, Emery CA, Wiley JP, Ferber R (2015) The effect of the addition of hip strengthening exercises to a lumbopelvic exercise programme for the treatment of non-specific low back pain: A randomized controlled trial. Journal of science and medicine in sport 18(6): 626-631.

Your next submission with Juniper Publishers
will reach you the below assets
- Quality Editorial service
- Swift Peer Review
- Reprints availability
- E-prints Service
- Manuscript Podcast for convenient understanding
- Global attainment for your research
- Manuscript accessibility in different formats
( Pdf, E-pub, Full Text, Audio)
- Unceasing customer service
Track the below URL for one-step submission
https://juniperpublishers.com/online-submission.php

